\title{
Electroacupuncture at the Zusanli and Baihui acupoints ameliorates type-2 diabetes-induced reductions in proliferating cells and differentiated neuroblasts in the hippocampal dentate gyrus with increasing brain-derived neurotrophic factor levels
}

\author{
Jin Young $\mathrm{CHUNG}^{1)}$, Dae Young $\mathrm{YOO}^{2)}$, Wooseok $\mathrm{IM}^{3)}$, Jung Hoon $\mathrm{CHOI}^{4)}$, Sun Shin $\mathrm{YI}^{5)}$, Hwa Young YOUN ${ }^{6}$, \\ In $\mathrm{Koo} \mathrm{HWANG}^{2}$, Je Kyung $\mathrm{SEONG}^{2)}$ and Yeo Sung YOON ${ }^{2) *}$ \\ ${ }^{1)}$ Department of Veterinary Internal Medicine and Geriatrics, College of Veterinary Medicine, Kangwon National University, Chuncheon \\ 200-701, Republic of Korea \\ ${ }^{2)}$ Department of Anatomy and Cell Biology, College of Veterinary Medicine, and Research Institute for Veterinary Science, Seoul National \\ University, Seoul 151-742, Republic of Korea \\ ${ }^{3)}$ Department of Neurology, Seoul National University Hospital, Seoul 110-744, Republic of Korea \\ ${ }^{4)}$ Department of Anatomy, College of Veterinary Medicine, Kangwon National University, Chuncheon 200-701, Republic of Korea \\ ${ }^{5)}$ Department of Biomedical Laboratory Science, College of Medical Sciences, Soonchunhyang University, Asan 336-745, Republic of \\ Korea \\ ${ }^{6)}$ Department of Veterinary Internal Medicine, College of Veterinary Medicine, and Research Institute for Veterinary Science, Seoul \\ National University, Seoul 151-742, Republic of Korea
}

(Received 5 August 2014/Accepted 3 October 2014/Published online in J-STAGE 22 October 2014)

ABSTRACT. In the current study, we investigated whether electroacupuncture (EA) can inhibit pathological reductions in neurogenesis. Zucker diabetic fatty (ZDF) rats at 7 weeks of age were anesthetized with zoletil, and sham-acupuncture or EA at the Zusanli (ST36) and Baihui (GV20) acupoints was administered once a day for 5 weeks. In the ZDF group that received sham-EA (ZDF-Sham group), the blood glucose level was significantly increased together with age as compared to the control littermates [Zucker lean control (ZLC) rat]. In contrast, proliferating cells and differentiated neuroblasts were significantly decreased in the ZDF-Sham group compared to the ZLC group. Although EA treatment decreased blood glucose levels, this was not statistically significant when compared to blood glucose levels changes in the ZDF-Sham group. However, proliferating cells and differentiated neuroblasts were significantly increased with EA in ZDF rats as compared to those in the ZDF-Sham group. Brain-derived neurotrophic factor (BDNF) levels were significantly decreased in hippocampal homogenates of ZDF-Sham group compared to those in the ZLC group. The EA treatment significantly increased the BDNF levels compared to those in the ZDF-Sham group, and BDNF levels in this group were similar to those in the ZLC group. These results suggest that EA at ST36 and GV20 can ameliorate the reductions in proliferating cells and differentiated neuroblasts in the dentate gyrus induced by type-2 diabetes without significantly reducing blood glucose levels with increasing BDNF levels.

KEY WORDS: brain-derived neurotrophic factor, electroacupuncture, hippocampus, neurogenesis, type 2 diabetes

doi: 10.1292/jvms.14-0400; J. Vet. Med. Sci. 77(2): 167-173, 2015

The brain has high levels of insulin receptors as well as insulin-sensitive glucose transporters. Chronic and untreated diabetes can cause cholinergic dysfunction as well as Alzheimer's disease [4, 10]. Diabetes significantly decreases the learning and memory functions $[18,34]$ and promotes cognitive impairment and vascular dementia in humans [3]. Previous studies have shown that diabetes decreases neurogenesis in the dentate gyrus [2, 14, 16, 19]. Several drugs intended for treatment of type- 2 diabetes have been developed and are shown to reduce blood glucose and leptin levels efficiently. However, some of these have significant side effects, such as weight gain and increased risk of myocardial infarction $[11,32,40]$.

*Correspondence to: Yoon, Y. S., Department of Anatomy and Cell Biology, College of Veterinary Medicine, Seoul National University, Seoul 151-742, South Korea. e-mail: ysyoon@snu.ac.kr (C)2015 The Japanese Society of Veterinary Science

This is an open-access article distributed under the terms of the Creative Commons Attribution Non-Commercial No Derivatives (by-nc-nd) License $<$ http://creativecommons.org/licenses/by-nc-nd/3.0/>.
Acupuncture is thought to be an effective alternative and complementary therapy without side effects. It involves the insertion of fine needles into specific points (acupoints), thereby regulating the energy in the body [23]. Electroacupuncture (EA) is a specific type of acupuncture in which needles are attached to a stimulator that produces continuous electric pulses. Recently, much attention has been devoted to EA as an effective alternative therapy which can improve both type- 1 and type- 2 diabetes. Among various acupoints, the Zusanli (ST36) acupoint is considered as a primary target to control blood glucose [24]. In addition, acupuncture at both the ST36 and the Baihui (GV20) acupoints has been shown to ameliorate the cognitive impairments found in multi-infarct and vascular dementia [38, 39]. In our previous studies, we noted that acupuncture or EA at the ST36 and GV20 acupoints significantly increased proliferating cells and differentiated neuroblasts in the dentate gyrus by increasing brain-derived neurotrophic factor (BDNF) and phospho-cAMP response element-binding protein (pCREB) $[12,13]$.

EA significantly reduces serum glucose levels by enhanc- 
ing insulin secretion $[6,15]$. In addition, EA significantly increases hippocampal neurogenesis as well as the levels of neurotrophic factors $[7,9,12,13,17,21,37]$. There are few reports to date describing the effects of EA in animal models of type-1 and type-2 diabetes particularly in relation to hippocampal neurogenesis. In the current study, we investigate whether EA at the ST36 and GV20 acupoints prevents and improves type-2 diabetes by examining changes in proliferating cells and differentiated neuroblasts in the hippocampal dentate gyrus by using Ki67, an endogenous marker of proliferating cells expressed during all active cell cycles, except G0 and early G1 phases [8], and by using doublecortin (DCX), a marker of differentiated neuroblasts expressed in immature neurons from 1 to 28 days of cell age [5].

\section{MATERIALS AND METHODS}

Experimental animals: Male and female heterozygoustype $\left(\right.$ Lepr $\left.^{f a /+}\right)$ Zucker diabetic fatty (ZDF) rats were purchased from Genetic Models (Indianapolis, ME, U.S.A.) and bred in-house prior to experimental use. They were housed in animal facilities maintained at $23^{\circ} \mathrm{C}$ with $60 \%$ humidity and a 12-hr light/dark cycle, with free access to food and tap water. Purina 5008 rodent diets $(7.5 \%$ fat $)$ were provided as recommended by Genetic Models Co. (Purina, St. Louis, MO, U.S.A.). Animal handling and care conformed to guidelines established by current international laws and policies (NIH Guide for the Care and Use of Laboratory Animals, NIH Publication No. 85-23, 1985, revised 1996) and were approved by the Institutional Animal Care and Use Committee of Seoul National University. All experiments and procedures were designed to minimize the number of animals used and the suffering caused.

Genotyping for the $f a$ gene and experimental design: Genotyping for the $f a$ gene was performed as described previously [14]. To measure the effects of EA on diabetic onset, proliferating cells and differentiated neuroblasts in the hippocampus, ZDF rats were randomly assigned into shamacupuncture (ZDF-Sham) and EA (ZDF-EA) groups $(n=9$ in each group). ZDF rats show insulin insufficiency starting at 7- or 8-week of age, as well as impairments in glucose disposal and hepatic glucose suppression [35]. Zucker lean control (ZLC) rats $(n=9)$ were used in the control group. At 7 weeks of age, animals were anesthetized with $30 \mathrm{mg} / \mathrm{kg}$ Zoletil $50^{\circledR}$ (Virbac, Carros, France), and sham-acupuncture or EA was administered once a day for 5 weeks in ZDF rats. ZDF-sham group was made by acupuncture at nearby nonacupoints in the hamstring muscles and temporal muscle. For ZDF-EA group, acupoints used were the ST36 of both legs ( $5 \mathrm{~mm}$ below the head of the fibula under the knee joint and $2 \mathrm{~mm}$ lateral to the anterior tubercle of the tibia) and the GV20 (located at the midmost point between the bilateral parietal bones, forward insertion). Stainless steel needles, measuring $0.25 \times 20 \mathrm{~mm}$, with a guide-tube (Wujiang Shenli Medical \& Health Material Co., Ltd., Wujiang, China) were inserted into the skin at a depth of $5 \mathrm{~mm}$. Electric stimulation was administered by an EA apparatus (Model G-6805) for 20 min. Stimulation parameters consisted of disperse-dense waves of $5 / 20 \mathrm{~Hz}$ (28.5 msec/15 msec pulse duration) in frequency and a current density of 2-4 mA.

Measurement of blood glucose levels and tissue processing for histology: To measure blood glucose concentrations, a small amount of blood was sampled each morning (09:00A.M.) by pricking the tail using a $27 \mathrm{G}$ needle and was analyzed using a blood glucose monitor (Ascensia Elite XL Blood Glucose Meter, Bayer, Toronto, Canada).

For immunohistochemical analysis, animals in each group $(n=5)$ were anesthetized with $30 \mathrm{mg} / \mathrm{kg}$ Zoletil $50^{\circledR}$ at 12 weeks of age and transcardially perfused with $0.1 \mathrm{M}$ phosphate-buffered saline (PBS, $\mathrm{pH} 7.4$ ) followed by $4 \%$ paraformaldehyde in $0.1 \mathrm{M}$ phosphate buffer ( $\mathrm{pH} 7.4)$. The brains were removed and post-fixed in the same fixative for $12 \mathrm{hr}$. The brains were then cryoprotected by overnight incubation in $30 \%$ sucrose and sectioned coronally in $30-\mu \mathrm{m}-$ thick slices using a cryostat (Leica, Wetzlar, Germany). The slices were collected into six-well plates containing PBS for further processing.

Immunohistochemistry for Ki67 and DCX: To optimize consistency of our immunohistochemistry data for Ki67 and DCX staining, sections were carefully processed simultaneously and under identical conditions. Tissue sections used were collected from the region between 3.00 and $4.08 \mathrm{~mm}$ caudal to the bregma as localized with the help of the rat brain atlas [29]. Ten sections, $90-\mu \mathrm{m}$ apart, were sequentially treated with $0.3 \%$ hydrogen peroxide in PBS for 30 min and $10 \%$ normal horse serum in $0.05 \mathrm{M}$ PBS. They were next incubated with rabbit anti-Ki67 antibody (1:1,000; Abcam, Cambridge, U.K.) or goat anti-DCX antibody (1:50; Santa Cruz Biotechnology, Santa Cruz, CA, U.S.A.) overnight and were subsequently exposed to biotinylated rabbit anti-goat IgG (diluted 1:200, Vector, Burlingame, CA, U.S.A.) and streptavidin peroxidase complex (diluted 1:200, Vector). Visualization was performed by incubation with 3, 3'-diaminobenzidine tetrahydrochloride and hydrogen peroxide.

The number of Ki67- and DCX-immunoreactive cells in each section of the dentate gyrus group was counted using an image analysis system (Optimas 6.5, CyberMetrics, Scottsdale, AZ, U.S.A.) equipped with a computer-based CCD camera. The cell counts from all sections of all rats were averaged.

Measurement of BDNF levels in the hippocampus: For measuring BDNF levels in the hippocampus, animals in each group $(n=4)$ were anesthetized with $30 \mathrm{mg} / \mathrm{kg}$ Zoletil $50^{\circledR}$ at 12 weeks of age, and the bilateral hippocampi were quickly removed from the brain and put into labeled cryotubes. After a quick-freeze in liquid nitrogen for $15 \mathrm{~min}$, the bilateral hippocampi were stored in a freezer at $-80^{\circ} \mathrm{C}$ for further analyses.

Bilateral hippocampi were homogenized in a cell lysis buffer solution according to the manufacturer's instructions from the ELISA kit. Moreover, the determination of total protein was performed using a BCA Protein Assay Kit (Thermo Scientific, Rockford, IL, U.S.A.). The data were corrected with total protein concentrations to calculate the content of BDNF protein. Furthermore, the relative concentration was expressed as $n \mathrm{~g} / \mathrm{g}$ wet weight in the tissue. 
Statistical analysis: All data shown are expressed as mean \pm standard error of the mean (SEM). Differences among the means were statistically analyzed using a one-way analysis of variance followed by Bonferroni's multiple comparison test to compare individual groups. Statistical significance was set to $P<0.05$.

\section{RESULTS}

Effects of EA on blood glucose at the onset of type-2 diabetes: The mean blood glucose level in the ZLC group was $6.42 \pm 0.52 \mathrm{mM}$ at 6 weeks of age and remained at similar levels up to 12 weeks of age. In the ZDF-Sham and ZDFEA groups, blood glucose levels were significantly higher (9.04 \pm 0.61 and $9.00 \pm 0.63 \mathrm{mM}$, respectively) than those in the ZLC group at 6 weeks of age. There were no significant differences between ZDF-Sham and ZDF-EA groups. The blood glucose levels in both of these groups increased with age. The blood glucose level was lower in the ZDF-EA group $(17.23 \pm 1.14 \mathrm{mM})$ as compared to that in the ZDFSham group $(20.50 \pm 1.08 \mathrm{mM})$ at 12 weeks of age (Fig. 1).

Effects of EA on proliferating cells at the onset of type-2 diabetes: In all groups, Ki67-positive nuclei were mainly detected in the subgranular zone of dentate gyrus. However, the number of Ki67-positive nuclei was significantly different among groups. In the ZDF-Sham group, fewer Ki67positive nuclei were detected in the subgranular zone of the dentate gyrus than in the ZLC group (Fig. 2A, 2B and 2D). In the ZDF-EA group, the number of Ki67-positive nuclei was significantly increased as compared to that in the ZDFSham group and higher as compared to the ZLC group (Fig. $2 \mathrm{C}$ and $2 \mathrm{D}$ ).

Effects of EA on neuroblast differentiation at the onset of type-2 diabetes: In the ZLC group, DCX-immunoreactive neuroblasts were observed in the dentate gyrus. They had well-developed dendrites which extended into the molecular layer across the granule cell layer of the dentate gyrus (Fig. $3 \mathrm{~A}$ and $3 \mathrm{~B}$ ). In the ZDF-Sham group, the number of DCXimmunoreactive neuroblast was significantly decreased as compared to that in the ZLC group (Fig. 3G). In addition, the dendrites of DCX-immunoreactive neuroblasts were poorly developed as compared to those in the ZLC group (Fig. $3 \mathrm{C}$ and $3 \mathrm{D}$ ). In the ZDF-EA group, DCX-immunoreactive neuroblasts had well-developed dendrites, and the number of DCX-immunoreactive neuroblasts was significantly increased as compared to that in the ZDF-Sham group (Fig. $3 \mathrm{E}, 3 \mathrm{~F}$ and $3 \mathrm{G})$.

Effects of EA on BDNF levels at the onset of type-2 diabetes: In the ZLC group, BDNF levels were $17.08 \pm$ $1.99 \mathrm{ng} / \mathrm{g}$ wet weight in the hippocampal homogenates. In the ZDF-Sham group, BDNF levels were significantly decreased to $67.1 \%$ of ZLC group. EA treatment to ZDF group significantly increased the BDNF levels, which were similar to those in the ZLC group (Fig. 4).

\section{DISCUSSION}

Diabetes mellitus is one of most prevalent diseases in

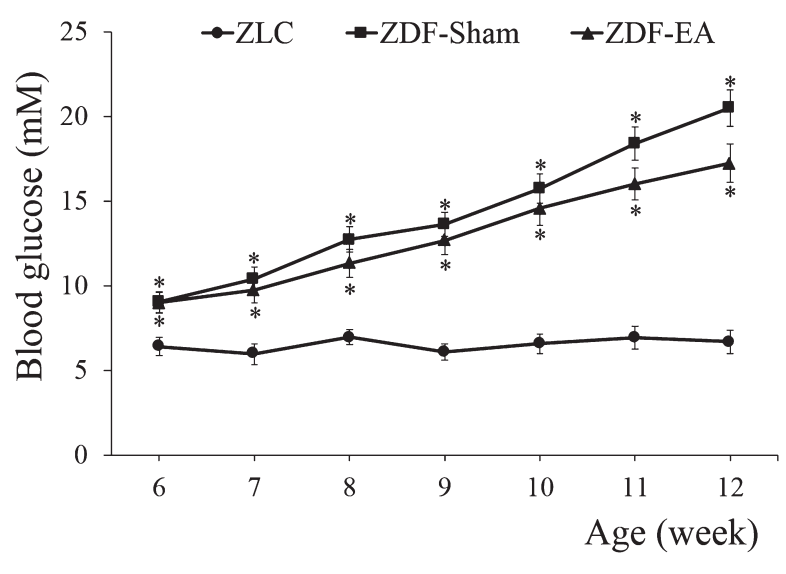

Fig. 1. Age-related changes in blood glucose levels in ZLC, ZDFSham and ZDF-EA rats. Blood glucose concentration levels are unchanged in the ZLC group. However, both the ZDF-Sham and ZDF-EA groups show significantly increasing blood glucose levels correlating with age. At 12 weeks of age, the blood glucose levels are low in the ZDF-EA group as compared to the ZDF-Sham group ( $n=9$ per group; $* P<0.05$, significantly different from the ZLC group). There are no significant differences in blood glucose levels between ZDF-Sham and ZDF-EA groups at experimental ages. Bars indicate means $\pm \mathrm{SEM}$.

the world population and can cause severe damage to many structures in the body. It has been previously reported that EA exhibits potent hypoglycemic effects in type-2 diabetes by inducing insulin secretion [6]. In the current study, we also investigated whether EA can be validated as a therapeutic approach for diabetes. Although EA decreased the fed blood glucose levels, we did not observe statistical significance. This result is consistent with a previous study in which EA decreased glycated hemoglobin in the absence of statistical significance [22]. EA administered at $15 \mathrm{~Hz}$ on the ST36 acupoint has been shown to enhance insulin sensitivity in steroid-induced insulin resistant male rats [24]. In type-2 diabetic $d b / d b$ mice, EA at the ST36 and CV4 (Guanyuan) acupoints further significantly reduces the fasting blood glucose levels as compared to untreated littermates after 6-8 weeks of treatment [22]. It is likely that the feeding state of the animal and diet composition may have influenced the results of the above studies as this has been previously shown to affect proliferating cells and differentiated neuroblasts [1, $28,30]$.

We observed effects of EA on proliferating cells and differentiated neuroblasts in the dentate gyrus of type- 2 diabetic rats. Type- 2 diabetes significantly decreases proliferating cells and differentiated neuroblasts as shown by previous studies in which type-2 diabetes has been shown to reduce hippocampal neurogenesis in various animal models of type-2 diabetes $[2,14,19]$. In Goto-Kakizaki rats, the onset of type-2 diabetes significantly reduced the survived cells in the dentate gyrus and subventricular zone of lateral ventricle compared to that in the control (Wistar-Kyoto) rats [19]. Mice showed significant reduction in the rate of neurogenesis in a spontaneous model of type-1 diabetes compared 

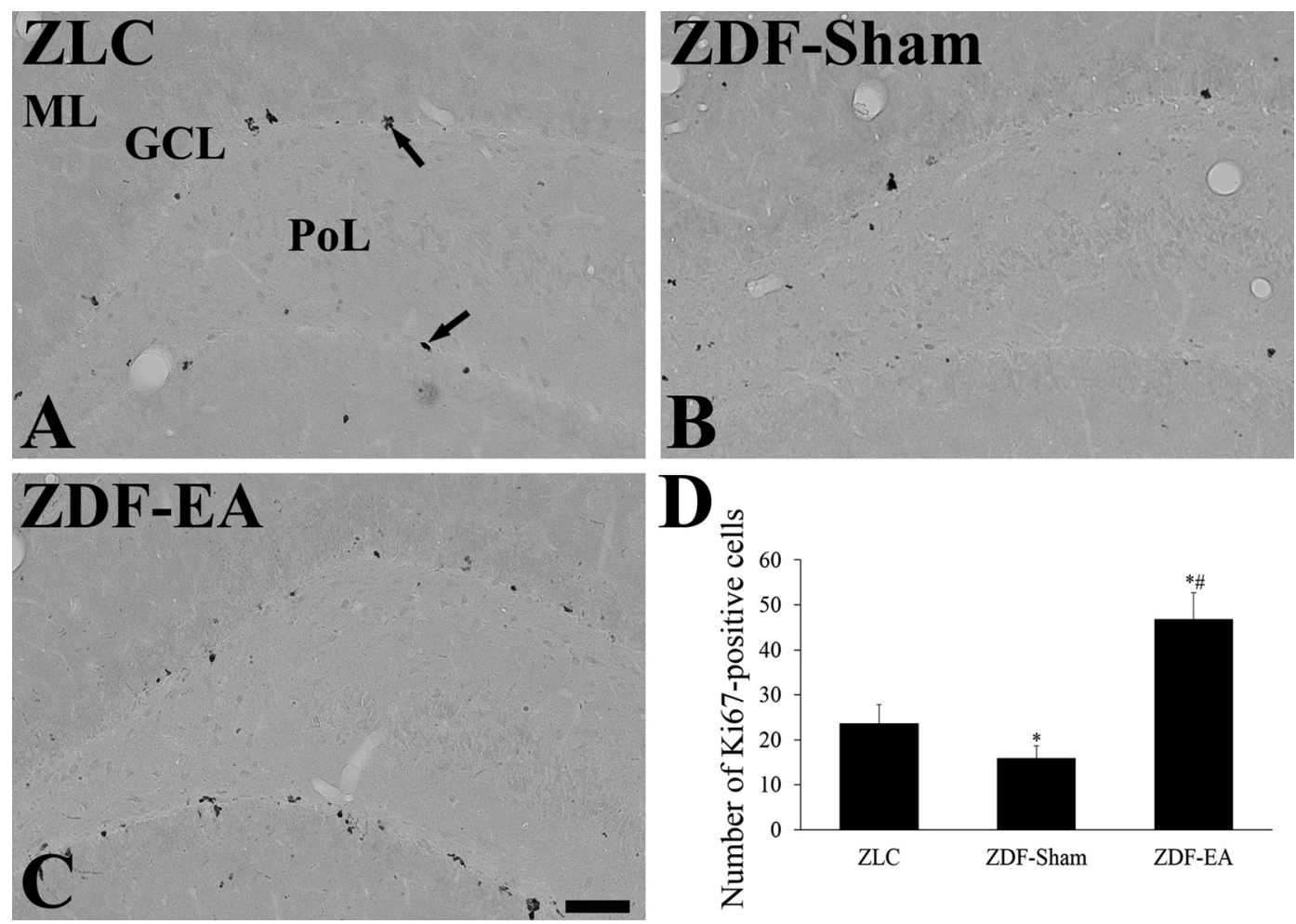

Fig. 2. Immunohistochemistry for Ki67 in the dentate gyrus in ZLC (A), ZDF-Sham (B) and ZDF-EA (C) rats. In the ZLC group, Ki67-positive nuclei (arrows) are detected in the dentate gyrus. In the ZDF-Sham group, fewer Ki67positive nuclei are observed in the dentate gyrus as compared to those in the ZLC group. In the ZDF-EA group, abundant Ki67-positive nuclei are detected in the dentate gyrus. GCL, granule cell layer; ML, molecular layer; PoL, polymorphic layer. Scale bar $=100 \mu \mathrm{m}$. D: Quantitative analysis of Ki67-positive nuclei per section in the ZLC, ZDFSham and ZDF-EA rats using image analyzer ( $n=5$ per group; $* P<0.05$, significantly different from the ZLC group, $\# P<0.05$, significantly different from the ZDF-Sham group). Bars indicate means \pm SEM.

to control strains [2]. Our finding that EA significantly rescues the reduction of proliferating cells and differentiated neuroblasts in the dentate gyrus of type-2 diabetic rats is also consistent with previous studies.

In the present study, we also investigated the BDNF levels in the hippocampal homogenates, because BDNF plays important roles in the neurogenesis in the hippocampal region $[27,31]$. BDNF mRNA is overlapped with BDNF receptor (tyrosine receptor kinase $\mathrm{B}$ ) in the neurons of the hippocampus. The synthesis and putative release of BDNF from neurons and/or dendritic sites within the hippocampus provide evidence of a potential autocrine or paracrine role for BDNF [36]. In the present study, EA treatment to ZDF group significantly increased the BDNF levels in the hippocampal homogenates. This result was strongly supported by a previous study that EA has been shown to efficiently increase proliferating cells and differentiated neuroblasts by increasing BDNF as well as pCREB in naive rats $[12,13]$. Surprisingly, proliferating cells and differentiated neuroblasts were more abundant in the EA-ZDF group as compared to those in the control (ZLC) group. It has been reported that rats fed highfat, high-glucose diet exhibit impaired spatial learning ability, reduced hippocampal dendritic spine density and reduced long-term potentiation at Schaffer collateral-CA1 synapses with reductions in levels of BDNF in the hippocampus [33].

Acupuncture or EA reverses the reduced performance in memory tasks and decreased hippocampal acetylcholine levels in the animal models of stress $[20,26]$. In addition, EA ameliorates symptoms of neurological diseases, such as Alzheimer's disease, and stroke by increasing neurogenesis $[17,21]$. The effect of EA on central cholinergic deficits or hippocampal neurogenesis has been found to be correlated to changes in nerve growth factor [25] and BDNF [12].

In conclusion, we have shown that EA administered to type-2 diabetic rats decreases blood glucose levels and increases proliferating cells and differentiated neuroblasts. This result suggests that EA can be clinically relevant for diabetic patients to improve hippocampal functions.

ACKNOWLEDGMENT. This work was supported by a National Research Foundation of Korea Grant funded by the Korean Government (MEST), Republic of Korea (20090074273) and by 2013 Research Grant of Kangwon National University. 

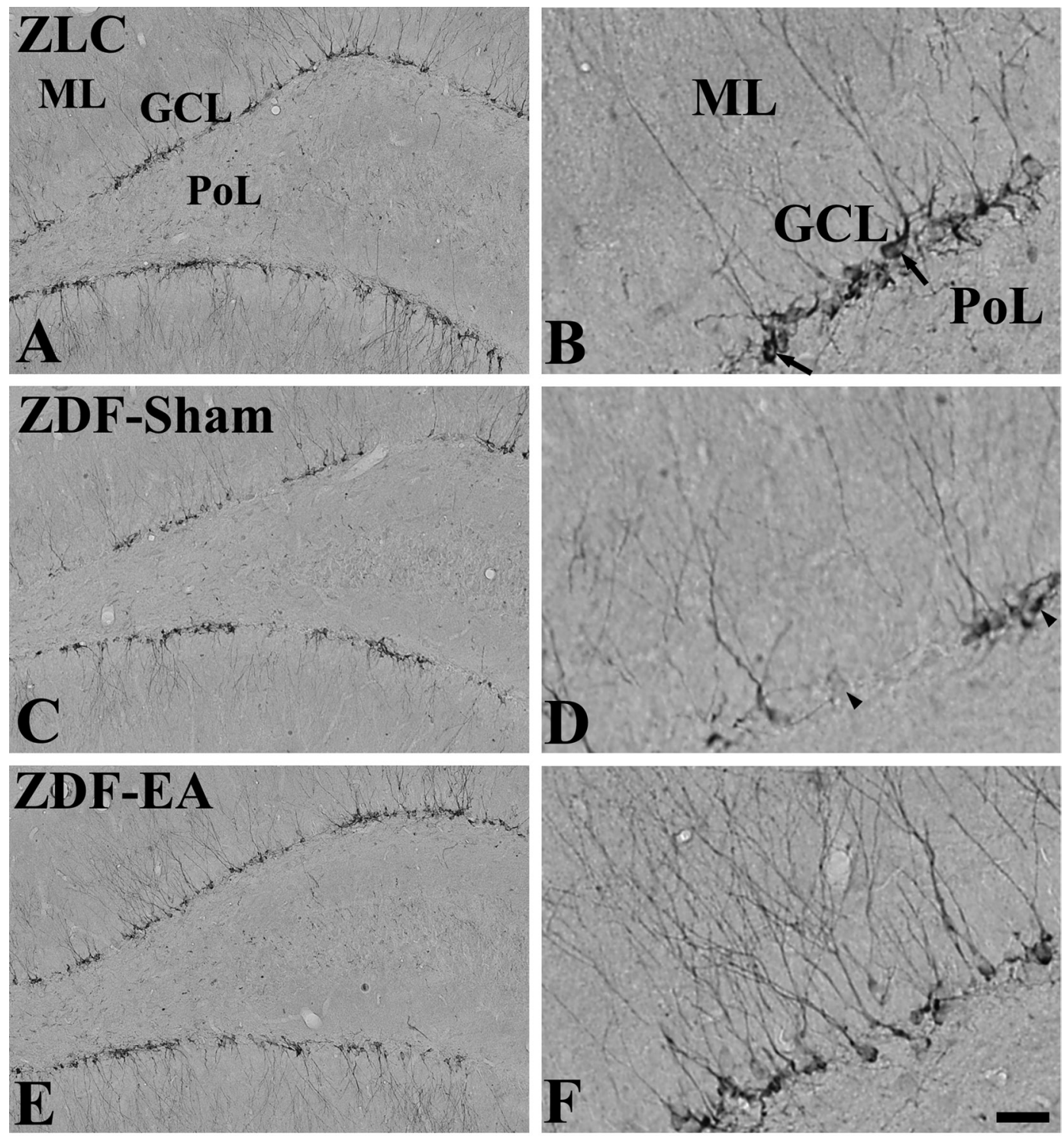
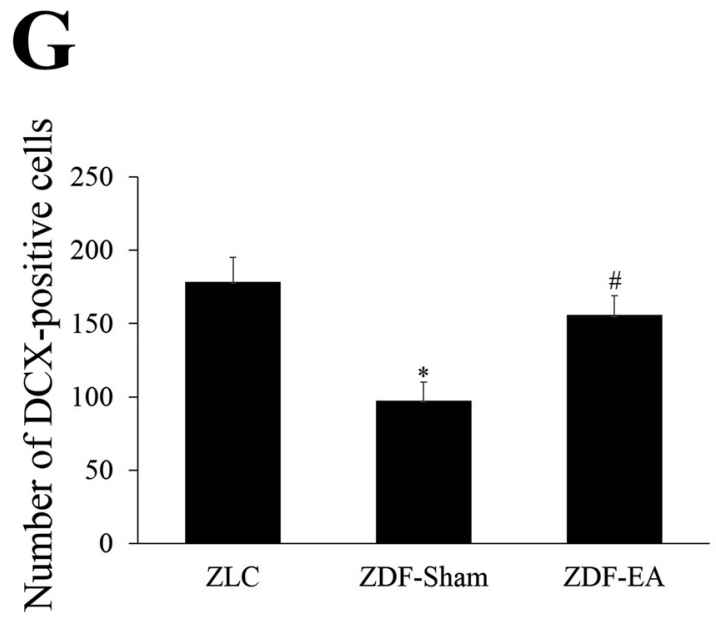

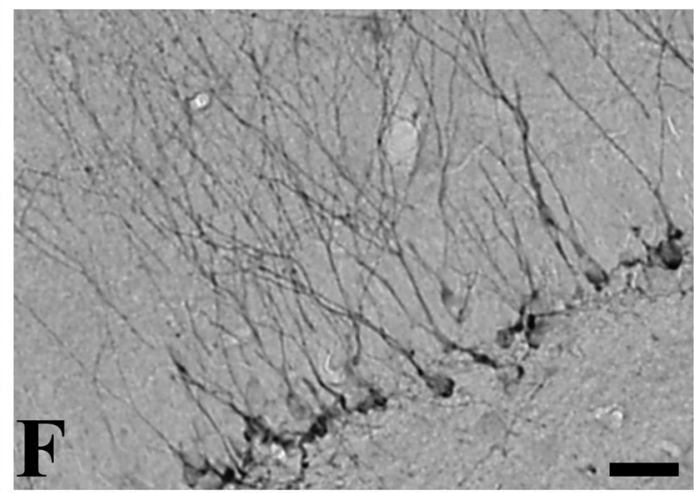

Fig. 3. Immunohistochemistry for DCX in the dentate gyrus in ZLC (A and B), ZDF-Sham (C and D) and ZDF-EA ( $\mathrm{E}$ and $\mathrm{F}$ ) rats. In the ZLC group, the somas of DCX-immunoreactive neuroblasts are detected in the subgranular zone of the dentate gyrus. Dendrites (arrows) are well developed and extended into the molecular layer (ML). In the ZDF-Sham group, DCX-immunoreactive neuroblasts are significantly decreased as compared to the ZLC group. In some neuroblasts (arrowheads), DCX-immunoreactive dendrites are particularly poorly developed. In the ZDF-EA group, DCX-immunoreactive neuroblasts with well-developed dendrites are abundant in the dentate gyrus. GCL, granule cell layer; PoL, polymorphic layer. Scale bar $=100 \mu \mathrm{m}(\mathrm{A}, \mathrm{C}$ and E) and $25 \mu \mathrm{m}$ (B, D and F). G: Analysis of DCX-immunoreactive neuroblasts per section in the ZLC, ZDF-Sham and ZDF-EA rats $(n=5$ per group; $* P<0.05$, significantly different from the ZLC group, $\# P<0.05$, significantly different from the ZDF-Sham group). Bars indicate means \pm SEM. 


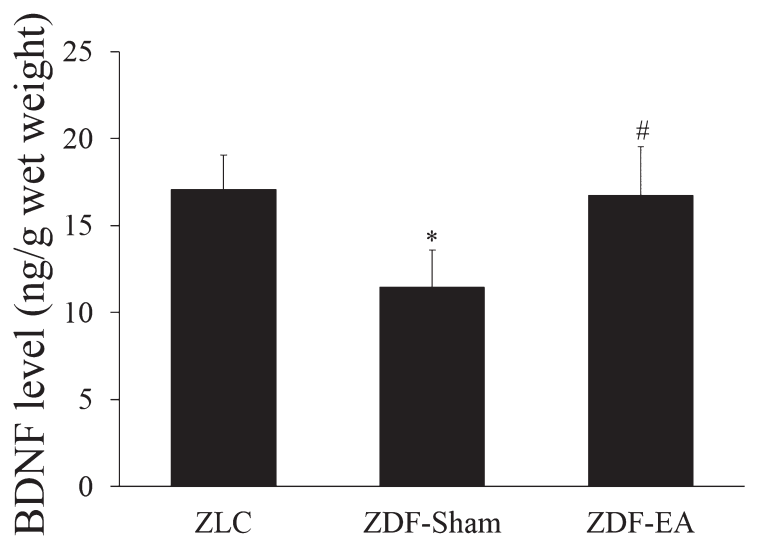

Fig. 4. BDNF levels in the hippocampi of ZLC, ZDF-Sham and ZDF-EA rats. Note that BDNF levels are significantly decreased in the ZDF-Sham group and reversed EA treatment $(n=4$ per group; ${ }^{*} P<0.05$, significantly different from the ZLC group, $\# P<0.05$, significantly different from the ZDF-Sham group). Bars indicate means \pm SEM.

\section{REFERENCES}

1. Akazawa, Y., Kitamura, T., Fujihara, Y., Yoshimura, Y., Mitome, M. and Hasegawa, T. 2013. Forced mastication increases survival of adult neural stem cells in the hippocampal dentate gyrus. Int. J. Mol. Med. 31: 307-314. [Medline]

2. Beauquis, J., Roig, P., De Nicola, A. F. and Saravia, F. 2009. Neuronal plasticity and antidepressants in the diabetic brain. Ann. N. Y. Acad. Sci. 1153: 203-208. [Medline] [CrossRef]

3. Biessels, G. J., Deary, I. J. and Ryan, C. M. 2008. Cognition and diabetes: a lifespan perspective. Lancet Neurol. 7: 184-190. [Medline] [CrossRef]

4. Biessels, G. J. and Kappelle, L. J. Utrecht Diabetic Encephalopathy Study Group 2005. Increased risk of Alzheimer's disease in Type II diabetes: insulin resistance of the brain or insulin-induced amyloid pathology? Biochem. Soc. Trans. 33: 1041-1044. [Medline] [CrossRef]

5. Brown, J. P., Couillard-Després, S., Cooper-Kuhn, C. M., Winkler, J., Aigner, L. and Kuhn, H. G. 2003. Transient expression of doublecortin during adult neurogenesis. J. Comp. Neurol. 467: 1-10. [Medline] [CrossRef]

6. Chang, S. L., Lin, J. G., Chi, T. C., Liu, I. M. and Cheng, J. T. 1999. An insulin-dependent hypoglycaemia induced by electroacupuncture at the Zhongwan (CV12) acupoint in diabetic rats. Diabetologia 42: 250-255. [Medline] [CrossRef]

7. Cheng, S., Ma, M., Ma, Y., Wang, Z., Xu, G. and Liu, X. 2009. Combination therapy with intranasal NGF and electroacupuncture enhanced cell proliferation and survival in rats after stroke. Neurol. Res. 31: 753-758. [Medline] [CrossRef]

8. Cooper-Kuhn, C. M. and Kuhn, H. G. 2002. Is it all DNA repair? Methodological considerations for detecting neurogenesis in the adult brain. Brain Res. Dev. Brain Res. 134: 13-21. [Medline] [CrossRef]

9. Gao, J., Wang, S., Wang, X. and Zhu, C. 2011. Electroacupuncture enhances cell proliferation and neuronal differentiation in young rat brains. Neurol. Sci. 32: 369-374. [Medline] [CrossRef]

10. Gispen, W. H. and Biessels, G. J. 2000. Cognition and synaptic plasticity in diabetes mellitus. Trends Neurosci. 23: 542-549.
[Medline] [CrossRef]

11. Graham, D. J., Ouellet-Hellstrom, R., MaCurdy, T. E., Ali, F., Sholley, C., Worrall, C. and Kelman, J. A. 2010. Risk of acute myocardial infarction, stroke, heart failure, and death in elderly Medicare patients treated with rosiglitazone or pioglitazone. JAMA 304: 411-418. [Medline] [CrossRef]

12. Hwang, I. K., Chung, J. Y., Yoo, D. Y., Yi, S. S., Youn, H. Y., Seong, J. K. and Yoon, Y. S. 2010. Effects of electroacupuncture at Zusanli and Baihui on brain-derived neurotrophic factor and cyclic AMP response element-binding protein in the hippocampal dentate gyrus. J. Vet. Med. Sci. 72: 1431-1436. [Medline] [CrossRef]

13. Hwang, I. K., Chung, J. Y., Yoo, D. Y., Yi, S. S., Youn, H. Y., Seong, J. K. and Yoon, Y. S. 2010. Comparing the effects of acupuncture and electroacupuncture at Zusanli and Baihui on cell proliferation and neuroblast differentiation in the rat hippocampus. J. Vet. Med. Sci. 72: 279-284. [Medline] [CrossRef]

14. Hwang, I. K., Yi, S. S., Kim, Y. N., Kim, I. Y., Lee, I. S., Yoon, Y. S. and Seong, J. K. 2008. Reduced hippocampal cell differentiation in the subgranular zone of the dentate gyrus in a rat model of type II diabetes. Neurochem. Res. 33: 394-400. [Medline] [CrossRef]

15. Ishizaki, N., Okushi, N., Yano, T. and Yamamura, Y. 2009. Improvement in glucose tolerance as a result of enhanced insulin sensitivity during electroacupuncture in spontaneously diabetic Goto-Kakizaki rats. Metabolism 58: 1372-1378. [Medline] [CrossRef]

16. Jackson-Guilford, J., Leander, J. D. and Nisenbaum, L. K. 2000. The effect of streptozotocin-induced diabetes on cell proliferation in the rat dentate gyrus. Neurosci. Lett. 293: 91-94. [Medline] [CrossRef]

17. Kim, Y. R., Kim, H. N., Ahn, S. M., Choi, Y. H., Shin, H. K. and Choi, B. T. 2014. Electroacupuncture promotes post-stroke functional recovery via enhancing endogenous neurogenesis in mouse focal cerebral ischemia. PLoS ONE 9: e90000. [Medline] [CrossRef]

18. Kodl, C. T. and Seaquist, E. R. 2008. Cognitive dysfunction and diabetes mellitus. Endocr. Rev. 29: 494-511. [Medline] [CrossRef]

19. Lang, B. T., Yan, Y., Dempsey, R. J. and Vemuganti, R. 2009. Impaired neurogenesis in adult type-2 diabetic rats. Brain Res. 1258: 25-33. [Medline] [CrossRef]

20. Lee, B., Sur, B. J., Kwon, S., Jung, E., Shim, I., Lee, H. and Hahm, D. H. 2012. Acupuncture stimulation alleviates corticosterone-induced impairments of spatial memory and cholinergic neurons in rats. Evid. Based Complement. Alternat. Med. 2012: 670536. [Medline] [CrossRef]

21. Li, X., Guo, F., Zhang, Q., Huo, T., Liu, L., Wei, H., Xiong, L. and Wang, Q. 2014. Electroacupuncture decreases cognitive impairment and promotes neurogenesis in the APP/PS1 transgenic mice. BMC Complement. Altern. Med. 14: 37. [Medline] [CrossRef]

22. Liang, F., Chen, R., Nakagawa, A., Nishizawa, M., Tsuda, S., Wang, H. and Koya, D. 2011. Low-frequency electroacupuncture improves insulin sensitivity in obese diabetic mice through activation of SIRT1/PGC-1 $\alpha$ in skeletal muscle. Evid. Based Complement. Alternat. Med. 2011: 735297. [Medline] [CrossRef]

23. Liao, T. J., Urata, S. and Nishikawa, H. 1998. Transient decrease in skin resistance response and level at the deh-chi stage caused by manual acupuncture. Tohoku J. Exp. Med. 186: 19-25. [Medline] [CrossRef]

24. Lin, R. T., Tzeng, C. Y., Lee, Y. C., Ho, W. J., Cheng, J. T., Lin, J. 
G. and Chang, S. L. 2009. Acute effect of electroacupuncture at the Zusanli acupoints on decreasing insulin resistance as shown by lowering plasma free fatty acid levels in steroid-background male rats. BMC Complement. Altern. Med. 9: 26. [Medline] [CrossRef]

25. Manni, L., Albanesi, M., Guaragna, M., Barbaro Paparo, S. and Aloe, L. 2010. Neurotrophins and acupuncture. Auton. Neurosci. 157: 9-17. [Medline] [CrossRef]

26. Manni, L., Aloe, L. and Fiore, M. 2009. Changes in cognition induced by social isolation in the mouse are restored by electroacupuncture. Physiol. Behav. 98: 537-542. [Medline] [CrossRef]

27. Noble, E. E., Billington, C. J., Kotz, C. M. and Wang, C. 2011. The lighter side of BDNF. Am. J. Physiol. Regul. Integr. Comp. Physiol. 300: R1053-R1069. [Medline] [CrossRef]

28. Patten, A. R., Moller, D. J., Graham, J., Gil-Mohapel, J. and Christie, B. R. 2013. Liquid diets reduce cell proliferation but not neurogenesis in the adult rat hippocampus. Neuroscience 254: 173-184. [Medline] [CrossRef]

29. Paxinos, G. and Watson, C.2007. The Rat Brain in Stereotaxic Coordinates. Elsevier Academic Press, Amsterdam.

30. Perera, T. D., Lu, D., Thirumangalakudi, L., Smith, E. L. P., Yaretskiy, A., Rosenblum, L. A., Kral, J. G. and Coplan, J. D. 2011. Correlations between hippocampal neurogenesis and metabolic indices in adult nonhuman primates. Neural Plast. 2011: 1-6. [Medline] [CrossRef]

31. Schmidt, H. D. and Duman, R. S. 2007. The role of neurotrophic factors in adult hippocampal neurogenesis, antidepressant treatments and animal models of depressive-like behavior. Behav. Pharmacol. 18: 391-418. [Medline] [CrossRef]

32. Shah, P. and Mudaliar, S. 2010. Pioglitazone: side effect and safety profile. Expert Opin. Drug Saf. 9: 347-354. [Medline] [CrossRef]
33. Stranahan, A. M., Norman, E. D., Lee, K., Cutler, R. G., Telljohann, R. S., Egan, J. M. and Mattson, M. P. 2008. Diet-induced insulin resistance impairs hippocampal synaptic plasticity and cognition in middle-aged rats. Hippocampus 18: 1085-1088. [Medline] [CrossRef]

34. van den Berg, E., Kloppenborg, R. P., Kessels, R. P. C., Kappelle, L. J. and Biessels, G. J. 2009. Type 2 diabetes mellitus, hypertension, dyslipidemia and obesity: A systematic comparison of their impact on cognition. Biochim. Biophys. Acta 1792: 470-481. [Medline] [CrossRef]

35. Wang, L., Tang, C. and Lai, X. 2004. Effects of electroacupuncture on learning, memory and formation system of free radicals in brain tissues of vascular dementia model rats. J. Tradit. Chin. Med. 24: 140-143. [Medline]

36. Wetmore, C., Olson, L. and Bean, A. J. 1994. Regulation of brain-derived neurotrophic factor (BDNF) expression and release from hippocampal neurons is mediated by non-NMDA type glutamate receptors. J. Neurosci. 14: 1688-1700. [Medline]

37. Yang, Z. J., Shen, D. H., Guo, X. and Sun, F. Y. 2005. Electroacupuncture enhances striatal neurogenesis in adult rat brains after a transient cerebral middle artery occlusion. Acupunct. Electrother. Res. 30: 185-199. [Medline]

38. Yu, J., Liu, C., Zhang, X. and Han, J. 2005. Acupuncture improved cognitive impairment caused by multi-infarct dementia in rats. Physiol. Behav. 86: 434-441. [Medline] [CrossRef]

39. Yu, J., Zhang, X., Liu, C., Meng, Y. and Han, J. 2006. Effect of acupuncture treatment on vascular dementia. Neurol. Res. 28: 97-103. [Medline] [CrossRef]

40. Ziyadeh, N., McAfee, A. T., Koro, C., Landon, J. and Arnold Chan, K. 2009. The thiazolidinediones rosiglitazone and pioglitazone and the risk of coronary heart disease: a retrospective cohort study using a US health insurance database. Clin. Ther. 31: 2665-2677. [Medline] [CrossRef] 